\title{
Skin Care in the Tattoo Parlor: A Survey of Tattoo Artists in New York City
}

\author{
Brooke E. Rosenbaum ${ }^{\mathrm{a}}$ Emily C. Milam ${ }^{\mathrm{a}}$ Lauren Seo $^{\mathrm{a}}$ Marie C. Leger ${ }^{\mathrm{a}} \mathrm{b}$ \\ ${ }^{a}$ Ronald O. Perelman Department of Dermatology, New York University School of Medicine, and ${ }^{\mathrm{b}}$ Department of \\ Dermatology, Weill Cornell Medical College, New York, N.Y., USA
}

\section{Key Words}

Tattooists · Tattoo artists · Tattoos · Public health .

Nonmedical professionals $\cdot$ Skin infections $\cdot$ Adverse tattoo reactions

\begin{abstract}
To understand the role that tattooists play in providing skin care advice, we conducted an online, survey-based study of 90 licensed tattooists in New York City. The survey asked tattooists about their exposure to adverse tattoo events, advising on tattoo removal/correction, behaviors regarding preexisting skin conditions and aftercare, confidence in addressing client questions about adverse events and preexisting conditions, and prior training about skin conditions related to tattoos. Most tattooists (92.8\%) reported being asked by clients to evaluate adverse tattoo reactions, $85 \%$ were asked about tattoo removal, and $90 \%$ were asked about the safety of getting a tattoo with a preexisting skin condition. About half (56.1\%) had received training about skin conditions related to tattoos. Tattooists with prior training reported higher rates of optimal skin care behaviors and higher confidence with tattoo-related skin conditions; $91.4 \%$ reported interest in skin care education. Tattooists play a major role in the skin health of their clients. Providing education for tattooists may improve skin care in populations less likely to see a dermatologist.

(c) 2016 S. Karger AG, Basel
\end{abstract}

\section{Introduction}

Decorative tattoos have been popular for centuries, with an increase in prevalence in recent years. In the USA, an estimated $24 \%$ of the population has at least one tattoo [1]. In Europe, the prevalence of tattoos is approximately $9-12 \%[2,3]$. There is increasing evidence that adverse skin reactions to tattoos, including infections and allergies, are common. European surveys of tattooed individuals report the prevalence of immediate adverse tattoo reactions as $15-68 \%$ and that of delayed reactions as 9-27\% among respondents [4-6]. A New York City (NYC) survey of tattooed individuals in Central Park showed that $4.3 \%$ of respondents experienced acute tattoo reactions and $6.0 \%$ suffered from chronic reactions lasting longer than 4 months [7].

Despite the prevalence of adverse tattoo reactions, people with tattoo-related problems infrequently seek help from medical professionals. In the NYC study, for example, less than one third of respondents saw a physician for their tattoo complaints. Instead, people with tattoo-related complications often seek help from tattoo artists. A recent survey showed that approximately $93 \%$ of tattooed individuals perceived tattooists as either 'knowledgeable' or 'very knowledgeable' about tattoo-related infections and allergies [8]. A study of tattooed adolescents reported that teens prefer to seek tattoo-related medical

\section{KARGER}

E-Mail karger@karger.com

www.karger.com/drm
(C) 2016 S. Karger AG, Basel

1018-8665/16/2324-0484\$39.50/0
Brooke E. Rosenbaum

New York University School of Medicine

240 East 38th Street, 12th floor

New York, NY 10016 (USA)

E-Mail Brooke.Rosenbaum@med.nyu.edu 
advice from commercial tattoo artists rather than physicians [9]. These studies suggest that tattooists may be the first line of medical care for people with adverse tattoo reactions.

Recent discussions in the dermatologic literature about hairdressers and massage therapists have highlighted the potential for nonmedical professionals in skin care and/or surveillance to play an important role in client care $[10,11]$. To better understand the role that tattoo artists play in providing skin care advice to their clients, we conducted a survey of tattooists in NYC. Our survey focused on several themes: tattooists' exposure to adverse tattoo reactions, their role in providing advice about tattoo removal/correction, behaviors regarding screening for atypical nevi and prior skin conditions, providing tattoo aftercare instructions, and confidence level in advising clients about such issues.

An understanding of the role of tattoo artists from a dermatologic perspective may improve our knowledge of adverse tattoo reaction epidemiology as well as inform potential public health collaborations between dermatologists and tattooists. To our knowledge, this study is the first assessment of professional tattooists' experiences observing and managing skin conditions.

\section{Materials and Methods}

For further details, see the supplementary materials (for all online suppl. material, see www.karger.com/doi/10.1159/000446345) [4, 6, 9-12] (fig. 1; online suppl. tables 1, 2).

\section{Results}

\section{Participant Demographics}

A list of 265 tattoo parlors was composed from the NYC listings on Yelp, a website containing public listings of local businesses [12]. A total of 159 tattoo parlors agreed to participate in the study (initial response rate of $60.0 \%)$. During the study period, 90 tattoo artists completed the survey, indicating that some tattooists who agreed to take the survey did not end up participating. The participant demographics are shown in online supplementary table 2. Most tattooists were male (72.2\%). The average age of participants was $35.9 \pm 7.7$ years. Most tattooists practiced in Brooklyn (35.6\%) or Manhattan (35.6\%). Tattooists reported an average of $11.4 \pm 6.9$ years of experience, with many tattooists $(30.3 \%)$ reporting 6-10 years of experience. Tattooists most commonly re-

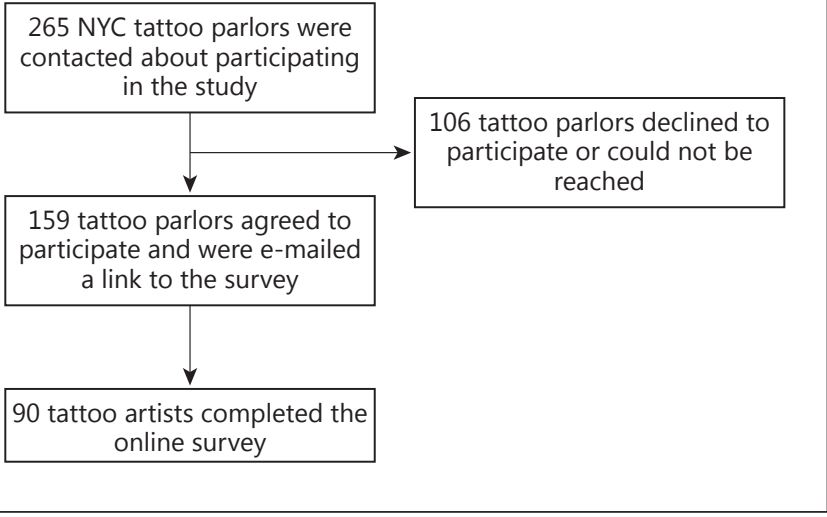

Fig. 1. Flowchart of Materials and Methods, demonstrating the process of participant recruitment and survey administration.

ported performing tattoos on 6-10 customers per week (49.4\%). The average price per hour of tattooing was USD $162.80 \pm 51.50$, with most tattooists $(39.7 \%)$ charging an average price of USD 150-199 per hour.

\section{Adverse Tattoo Reactions}

Overall, $92.8 \%$ of tattooists reported observing at least one adverse tattoo reaction, either related to a tattoo performed by themselves or by a different artist, during their careers. Tattooists reported encountering adverse tattoo reactions at an average frequency of $17.3 \pm 39.6$ times per year and ranging from once every 4 years to every day. Most tattoo artists reported encountering specific adverse tattoo reactions, ranging from $61.5 \%$ who reported encountering infections to $83.1 \%$ who reported color-specific reactions (fig. 2). Other customer complaints included 'blowouts' or subdermal dispersion of tattoo ink ( $\mathrm{n}=$ $2)$, chronic pruritus $(n=3)$, and developing 'pimples' at the site of tattoo $(\mathrm{n}=2)$. Most tattooists $(64.2 \%)$ also reported experiencing an adverse tattoo reaction on their own bodies. Approximately $76.3 \%$ of tattooists reported referring a client to a medical professional for care of an adverse tattoo reaction at least once. Tattooists most commonly referred clients to a dermatologist $(57.3 \%)$ or a primary care provider (51.2\%) (fig. 3).

\section{Tattoo Aesthetics}

Eighty-five percent of tattooists reported being asked about tattoo removal, with an average frequency of 50.8 \pm 75.8 times per year. Almost all tattooists (98.8\%) reported being asked about correcting over existing tattoos, at an average frequency of $123.1 \pm 142.3$ times per year. 
Fig. 2. Percentage of tattooists who reported observing or not observing select adverse tattoo reactions.

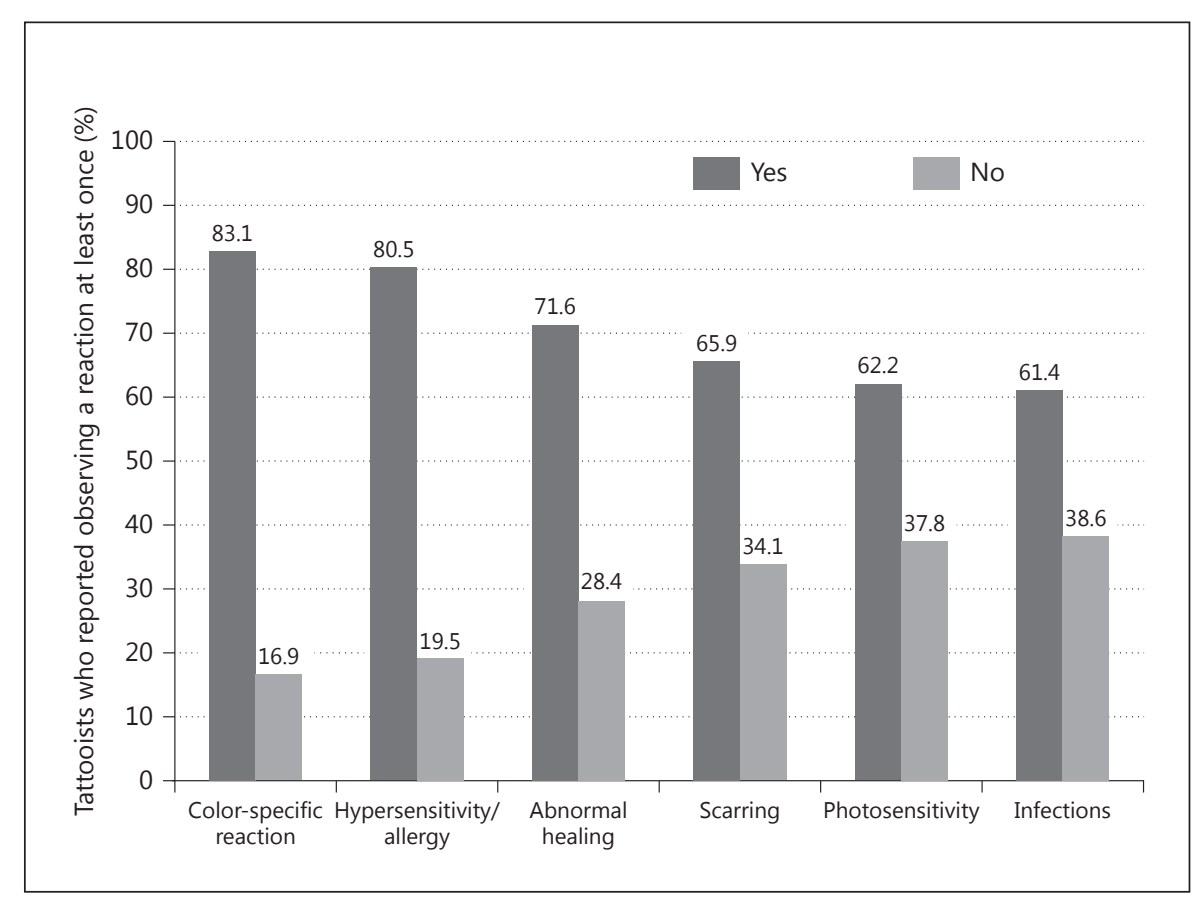

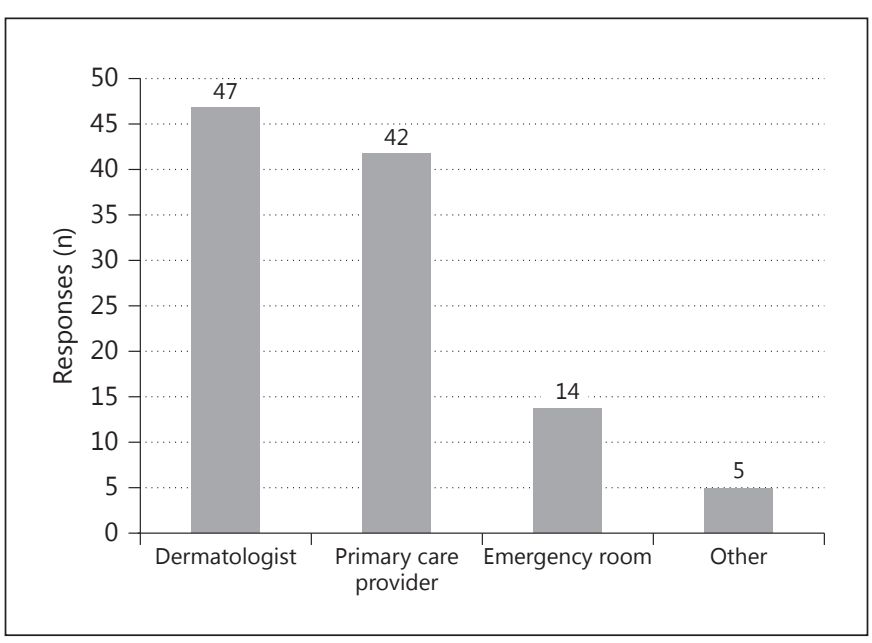

Fig. 3. Number of participating tattooists who reported referring clients to various medical professionals at least once for management of an adverse tattoo reaction.

\section{Tattooist Behaviors with Respect to Screening and Aftercare}

A summary of tattooist skin health behaviors is provided in table 1 . Ninety percent of tattooists reported being asked about the safety of getting a tattoo with a preexisting skin condition, at an average frequency of $11.2 \pm 13.4$ times per year. Seventy-one percent of tat-
Table 1. Tattooist skin care behaviors

\begin{tabular}{llll}
\hline Question & \multicolumn{2}{l}{ Responses, n (\%) } & \\
\cline { 2 - 4 } & always & sometimes & never \\
\hline $\begin{array}{l}\text { Do you ask your customers } \\
\text { if they have a preexisting } \\
\text { skin condition before giving } \\
\text { a tattoo? }\end{array}$ & $62(71.3)$ & $23(26.4)$ & $2(2.3)$ \\
\hline $\begin{array}{l}\text { Do you give customers } \\
\text { instructional handouts } \\
\text { about how to care for their } \\
\text { tattoos? }\end{array}$ & $73(83.9)$ & $13(14.9)$ & $1(1.1)$ \\
\hline $\begin{array}{l}\text { Do you ever look for/point } \\
\text { out atypical moles on the } \\
\text { skin while performing a } \\
\text { tattoo? }\end{array}$ & $48(55.2)$ & $28(32.2)$ & $11(12.6)$ \\
\end{tabular}

tooists reported that they always ask customers about preexisting skin conditions before administering a tattoo. Eighty-four percent of tattooists reported always providing instructional tattoo aftercare handouts. About half of the tattooists (55.2\%) reported always looking for atypical moles on customers' skin while performing a tattoo. 
Table 2. Tattooist skin care knowledge and education

\begin{tabular}{|c|c|c|}
\hline \multirow[t]{2}{*}{ Question } & \multicolumn{2}{|c|}{ Response, n (\%) } \\
\hline & yes & no \\
\hline \multirow{2}{*}{$\begin{array}{l}\text { Have you ever received formal training (class, reading material) about skin } \\
\text { conditions related to tattoos? } \\
\text { Would you be interested in additional training about skin conditions related } \\
\text { to tattoos if it was offered to you? }\end{array}$} & $46(56.1)$ & $36(43.9)$ \\
\hline & $74(91.4)$ & $7(8.6)$ \\
\hline \multicolumn{3}{|l|}{$\begin{array}{l}\text { How confident do you feel advising customers on how to treat/take care of } \\
\text { these kinds of skin complaints? }\end{array}$} \\
\hline Very confident & $33(38.4)$ & \\
\hline Somewhat confident & $30(34.9)$ & \\
\hline Neutral & $13(15.1)$ & \\
\hline Somewhat unconfident & $4(4.7)$ & \\
\hline Not at all confident & $2(2.3)$ & \\
\hline \multicolumn{3}{|l|}{$\begin{array}{l}\text { How confident do you feel advising these customers on the risks of getting a } \\
\text { tattoo with a preexisting skin condition? }\end{array}$} \\
\hline Very confident & $40(46.5)$ & \\
\hline Somewhat confident & $28(32.6)$ & \\
\hline Neutral & $15(17.4)$ & \\
\hline Somewhat unconfident & $0(0.0)$ & \\
\hline Not at all confident & $3(3.5)$ & \\
\hline \multicolumn{3}{|l|}{ Influence of prior skin care education } \\
\hline Always asking about preexisting skin conditions & $36(78.3)$ & $22(61.1)$ \\
\hline Always giving instructional handouts about tattoo aftercare & $41(89.1)$ & $28(77.8)$ \\
\hline Always checking for atypical moles while giving tattoos & $26(56.5)$ & $18(50.0)$ \\
\hline $\begin{array}{l}\text { Very/somewhat confident advising customers on managing adverse tattoo } \\
\text { reactions }\end{array}$ & $38(82.6)$ & $25(69.4)$ \\
\hline $\begin{array}{l}\text { Very/somewhat confident advising customers on the risks of getting a } \\
\text { tattoo with a preexisting skin condition }\end{array}$ & $39(84.8)$ & $25(69.4)$ \\
\hline
\end{tabular}

\section{Skin Care Confidence and Education}

Table 2 provides a summary of tattooist responses to questions about skin care knowledge and education. Most tattooists reported feeling very confident (38.4\%) or somewhat confident (34.9\%) when advising customers on how to manage adverse tattoo reactions. Most tattooists also reported feeling very confident (46.5\%) or somewhat confident (32.6\%) advising customers with a preexisting skin condition on the increased risks of getting a tattoo.

Approximately $56.1 \%$ of tattooists reported having received formal training about skin conditions related to tattoos (table 2). A higher percentage of tattooists who reported receiving prior education also reported always giving tattoo aftercare instructions, always asking about preexisting skin conditions, and always checking for atypical moles than those who reported never receiving prior education. Similarly, a higher percentage of tattooists who reported receiving prior education also reported high confidence when advising customers about the risks of getting a tattoo with a preexisting skin condition and when evaluating an adverse tattoo reaction than those who reported never receiving prior education. Approximately $91.4 \%$ of tattooists expressed interest in future education about skin conditions related to tattoos.

Many of the tattooists had questions they would want to ask a dermatologist. Common themes of these questions are displayed in table 3 . The most common questions were about proper tattoo aftercare $(n=5)$ and how to manage adverse tattoo reactions $(n=4)$.

\section{Discussion}

Professional tattooists represent a main point of preventative and tertiary skin care for their clients. They are responsible for describing the potential risks of the tattoo process, performing the tattoo procedure, recommending a proper aftercare regimen, and counseling customers on 
Table 3. Common themes of questions asked by tattooists for dermatologists

Question themes

Proper tattoo aftercare $(\mathrm{n}=5)$

Managing adverse tattoo reactions $(n=4)$

Effects of specific tattoo ink/materials on the skin $(n=3)$

Specific skin condition $(\mathrm{n}=3)$

Preventing scar formation $(\mathrm{n}=3)$

Adverse tattoo reaction pathophysiology $(n=2)$

Specific topical product $(\mathrm{n}=2)$

Skin healing pathophysiology $(\mathrm{n}=2)$

managing adverse tattoo reactions $[13,14]$. In fact, the intimate nature of the tattooist-client relationship has been described as resembling a patient-doctor interaction [15]. Our study showed that educating tattoo artists about adverse tattoo reactions and other skin conditions may improve their ability to counsel clients and increase their likelihood of practicing optimal skin health behaviors. However, there is no standardized skin care training required for someone to become a tattooist. In NYC, tattoo artists must complete a 3-hour infection control course and pass a written examination in order to be issued an official Tattoo Artist License, but there is no required training on skin conditions not caused by infection. This suggests that the past skin care training reported by the tattooists in this study is likely of variable breadth and quality. Tattoo artists learn their trade from apprenticeships in tattoo parlors, and thus skin care training and practices among tattooists vary [16].

According to our results, tattooists are frequently asked questions about adverse tattoo events, especially color-specific reactions, hypersensitivity, and abnormal healing. Interestingly, more than $60 \%$ of respondents reported experiencing an adverse reaction to one of their own tattoos, which was greater than the $42.6 \%$ of tattoo artists from the French Tattoo Union who were recently surveyed about personal tattoo reactions [17]. Their clients also frequently ask about tattoo safety with preexisting skin conditions. Because of the role tattoo artists play as advisors on health-related issues, they may be powerful public health allies for dermatologists. Nonmedical professionals can reach populations that may not regularly see a dermatologist. The utility of hairdressers in detecting skin lesions on the head and neck and massage therapists in identifying abnormal lesions has already been discussed in the dermatologic literature; indeed, most massage therapy training programs now include a course on skin cancer identification $[10,11]$. Tattoo artists also have prolonged access to their clients' skin and can similarly be useful in public health endeavors.

Almost all tattooists reported interest in additional education about skin conditions, and many had questions they wanted to ask a dermatologist. Additional education may allow tattooists to better counsel clients on the risks and contraindications to tattooing, such as advising clients with preexisting skin conditions of their risk of Koebnerization [18-20]. Teaching tattooists to identify common adverse tattoo reactions may allow them to more confidently discriminate between adverse and benign conditions. For example, educating tattooists on the ABCDEs of melanoma may better equip them to evaluate skin lesions at the potential site of tattooing, particularly important for clients without regular access to dermatologists [21]. Additional education may empower tattooists to be advocates for skin health in their community, while improving quality of life and clinical outcomes for their clients.

Tattoo artists and dermatologists also share roles in the aesthetic improvement of tattoos. Our results show that tattoo artists are asked about tattoo correction and removal on a regular basis. Tattoo artists commonly perform corrective tattoos to hide another artist's aesthetically unpleasing work, but the ability of tattooists to perform laser tattoo removal is variable depending on local law. In New York State, laser tattoo removal is considered a medical procedure and may only be performed by licensed medical professionals, so we did not ask NYC tattoo artists about their experiences with laser removal. Studies suggest that laser removal by nonmedical professionals may be dangerous as they may not be equipped to manage complications of the procedure [22]. Further research in regions where laser tattoo removal by nonmedical professionals is legal is needed to understand laser removal practices of tattoo artists.

Of note, our study only describes the practices of licensed tattoo artists and does not capture the experiences of those performing tattoos illegally. According to a survey of tattooed people in German-speaking countries, approximately $2-4 \%$ of tattoos are performed illegally [4]. Illegal tattoos are acquired because of their markedly lower cost, availability, and appeal [14]. However, illegal tattoos have an increased risk of infection as they are often performed under insufficient aseptic conditions, are commonly made with homemade inks, and are administered without proper aftercare instructions [14, 23]. For example, an increased risk of hepatitis $\mathrm{C}$ transmission has been noted in nonprofessional tattoo parlors, whereas an increased risk has not been documented in professional establishments [24]. 
Our results were based on self-reported responses by nonmedical professionals, which prevented the precise clinical characterization and prevalence of reported reactions. While the survey was developed for laypeople to understand, certain terms used to describe skin conditions may have been misinterpreted from their intended meaning. Our survey population may also be biased towards those who are trusting of the medical profession or especially motivated to improve the quality of their practice. Moreover, it is possible that multiple tattoo artists employed by the same parlor completed the survey and that their responses may reflect the practices of the tattoo parlor rather than the individual artists. Certain shops may be affiliated with a specific tattooing association or union, which have been shown to be more compliant with health standards than nonaffiliated shops [25]. Finally, there is obviously geographic bias as only tattooists practicing in NYC, a large urban city, were surveyed. Of note, we received few responses from tattoo artists in the Bronx and Staten Island. Although there are fewer tattoo parlors in these boroughs, they were disproportionately underrepresented in our study.
In summary, our study provides evidence that tattooists can play a major role in the skin health of their clients and have an avid interest in additional skin care education. These nonmedical professionals may be well suited for surveillance of skin disease in the community, which could improve public access to quality skin care. There is great potential for collaboration between dermatologists and tattooists.

\section{Statement of Ethics}

This study was approved by the Institutional Review Board of New York University School of Medicine. There were no ethical breaches during the study.

\section{Disclosure Statement}

The authors have no conflicts of interest or commercial associations to disclose.

\section{References}

1 Laumann AE, Derick AJ: Tattoos and body piercings in the United States: a national data set. J Am Acad Dermatol 2006;55:413-421.

-2 Long GE, Rickman LS: Infectious complications of tattoos. Clin Infect Dis 1994;18:610 619.

-3 Stirn A, Brähler E, Hinz A: Prevalence, sociodemography, mental health and gender differences of tattooing and body piercing (in German). Psychother Psychosom Med Psychol 2006;56:445-449.

-4 Klügl I, Hiller KA, Landthaler M, Bäumler W: Incidence of health problems associated with tattooed skin: a nation-wide survey in German-speaking countries. Dermatol 2010;221: $43-50$.

5 Høgsberg T, Hutton Carlsen K, Serup J: High prevalence of minor symptoms in tattoos among a young population tattooed with carbon black and organic pigments. J Eur Acad Dermatol 2013;27:846-852.

-6 Hutton Carlsen K, Serup J: Photosensitivity and photodynamic events in black, red and blue tattoos are common: a 'Beach Study'. J Eur Acad Dermatol 2014;28:231-237.

7 Brady BG, Gold H, Leger EA, Leger MC: Selfreported adverse tattoo reactions: a New York City Central Park study. Contact Dermatitis 2015;73:91-99.

-8 Liszewski W, Kream E, Helland S, Cavigli A, Lavin BC, Murina A: The demographics and rates of tattoo complications, regret, and unsafe tattooing practices: a cross-sectional study. Dermatol Surg 2015;41:1283-1289.
9 Armstrong ML, Murphy KP: Tattooing: another adolescent risk behavior warranting health education. Appl Nurs Res 1997;10: 181-189.

10 Bailey EE, Marghoob AA, Orengo IF, Testa MA, White VR, Geller AC: Skin cancer knowledge, attitudes, and behaviors in the salon: a survey of working hair professionals in Houston, Texas. Arch Dermatol 2011;147: 1159-1165.

11 Campbell SM, Louie-gao Q, Hession ML, Bailey E, Geller AC, Cummins D: Skin cancer education among massage therapists: a survey at the 2010 meeting of the American Massage Therapy Association. J Cancer Educ 2013;28: 158-164.

12 Yelp. https://biz.yelp.com (accessed May 20, 2015).

13 Kristensen L: The technique and craftsmanship of tattooing in the professional tattoo parlour. Curr Probl Dermatol 2015;48:31-36.

14 Wedel Kristensen M: Tattooist-customer relationships in a diversified environment of professional tattooists and 'scratchers'. Curr Probl Dermatol 2015;48:45-47.

15 Serup J: Seamless prevention of adverse events from tattooing: integrated strategy emphasising the customer-tattooist interaction. Curr Probl Dermatol 2015;48:236-247.

16 Kluger N: Epidemiology of tattoos in industrialized countries. Curr Probl Dermatol 2015;48:6-20.
17 Kluger N: Self-reported tattoo reactions in a cohort of 448 French tattooists. Int J Dermatol 2015, DOI: 10.1111/ijd.13030.

18 Weiss G, Shemer A, Trau H: The Koebner phenomenon: review of the literature. J Eur Acad Dermatol Venereol 2002;16:241-248.

19 Kluger N: Cutaneous complications related to permanent decorative tattooing. Expert Rev Clin Immunol 2010;6363-6371.

20 Kluger N: Contraindications for tattooing. Curr Probl Dermatol 2015;48:76-87.

21 Kluger N, Thomas L: The dragon with atypical mole syndrome. Arch Dermatol 2008; 144 : 948-949.

22 Karsai S, Krieger G, Raulin C: Tattoo removal by non-professionals - medical and forensic considerations. J Eur Acad Dermatol Venereol 2010;24:756-762.

23 Food and Drug Administration. Think Before You Ink: Are Tattoos Safe? 2009. http://www. fda.gov/downloads/ForConsumers/ConsumerUpdates/UCM143401.pdf (accessed August 25, 2015).

24 Tohme RA, Holmberg SD: Transmission of hepatitis $\mathrm{C}$ virus infection through tattooing and piercing: a critical review. Clin Infect Dis 2012;54:1167-1178.

25 Lehman EJ, Huy J, Levy E, Viet SM, Mobley A, Mccleery TZ: Bloodborne pathogen risk reduction activities in the body piercing and tattooing industry. Am J Infect Control 2010; 38:130-138. 